\title{
Desmopressin and low-dose ACTH test in rheumatoid arthritis
}

\author{
L Foppiani, M Cutolo ${ }^{1}$, P Sessarego, A Sulli ${ }^{1}$, C Prete $^{1}$, B Seriolo ${ }^{1}$ and M Giusti \\ Cattedra di Endocrinologia, DiSEM, and ${ }^{1}$ Cattedra di Reumatologia, DiMI, Universita'di Genova, Genova, Italy \\ (Correspondence should be addressed to L Foppiani, DiSEM, Cattedra di Endocrinologia, Viale Benedetto XV n.6, 16132 Genova, Italy)
}

\begin{abstract}
Objective: To ascertain whether a different regulation and sensitivity of the hypothalamic-pituitaryadrenal axis exists and whether a type of cortisol resistance is present in rheumatoid arthritis (RA) patients, a chronic disease in whose pathogenesis modifications of the steroid milieu are involved. Design: We studied the basal and dynamic response of ACTH and adrenal steroids to various stimuli acting on the hypophysis or directly on the adrenal gland.

Methods: We studied ten RA patients (39.8 \pm 7.4 (S.D.) years), defined according to the American Rheumatism Association, and seven healthy control patients (34.1 \pm 9.6 (s.D.) years). All subjects underwent testing, in random order, with placebo, desmopressin (DDAVP) (10 $\mu \mathrm{g}$ i.v.), ovine corticotropin-releasing hormone (oCRH) $(1 \mu \mathrm{g} / \mathrm{kg}$ body weight) and low-dose ACTH (5 $\mu \mathrm{g}$ i.v.), during the follicular phase of two different menstrual cycles. Blood samples were collected at different times for ACTH and adrenal steroids assay. Baseline estradiol (E2), testosterone and IGF-I levels were also evaluated. All subjects collected urine specimens for $24 \mathrm{~h}$ urine free cortisol (UFC).

Results: No difference in E2, testosterone or UFC was found between RA patients and controls. IGF-I levels were significantly $(P<0.01)$ lower in RA patients $(110.6 \pm 6.4 \mu \mathrm{g} / \mathrm{l})$ than in controls $(207.0 \pm 37.9 \mu \mathrm{g} / \mathrm{l})$. Mean baseline dehydroepiandrosterone (DHEA) and $\Delta 4$-androstenedione levels of the four tests were significantly $(P<0.05)$ lower in RA patients than in controls. In RA, a negative correlation was found between mean DHEA levels, class of disease $(r=-0.67, P<0.05)$ and erythrocyte sedimentation rate $(r=-0.63, P<0.05)$. After placebo no difference in ACTH and cortisol area under curves (AUCs) was found between RA patients and controls. After DDAVP no cortisol or ACTH response was found in RA patients, while a significant $(P<0.05)$ ACTH release was found in controls. Only in RA patients was DDAVP able to induce a significant $(P<0.01)$ DHEA increase. After oCRH a similar significant response in ACTH $(P<0.05)$, cortisol $(P<0.01)$, and DHEA $(P<0.01)$ was found in both groups. After low-dose ACTH, a similar significant $(P<0.01)$ cortisol response was found in both RA patients and controls; indeed in RA patients DHEA AUC (2196.0 \pm $321.8 \mathrm{nmol} / \mathrm{l}$ per $90 \mathrm{~min})$ was significantly lower $(P<0.01)$ than DHEA AUC $(4280.8 \pm 749.0 \mathrm{nmol} / \mathrm{l}$ per $90 \mathrm{~min})$ in controls. A similar significant $(P<0.01)$, though not abnormal, 17-hydroxyprogesterone response to ACTH was found in both groups.

Conclusions: Our study underlines reduced adrenal steroid and IGF-I levels, but not the previously described cortisol resistance in RA patients; it shows that baseline and dynamic cortisol levels are 'normal' but inadequate in the setting of a sustained inflammatory disease like RA. The reduced basal and low-dose ACTH-induced DHEA levels could reflect both a reduced sensitivity of the adrenal gland to exogenous corticotropin and a decreased steroid synthesis due to a partial adrenal enzymatic defect (P450 17,20 lyase).
\end{abstract}

European Journal of Endocrinology 138 294-301

\section{Introduction}

Rheumatoid arthritis (RA) is an immunological disease whose pathogenesis involves modifications of the steroid milieu. It is generally accepted that RA patients show reduced adrenal steroid levels when compared with healthy subjects $(1,2)$. Indeed, it has been shown that androgen replacement in male patients with RA and low serum testosterone levels is able to improve the clinical features of the disease (3). There is considerable evidence that the hypothalamic-pituitary-adrenal
(HPA) axis contributes to the inhibition of inflammation and that adrenalectomy and glucocorticoid antagonists exacerbate inflammation in animal models $(4,5)$. It is well known that hypothalamic and pituitary factors such as corticotropin-releasing hormone (CRH), arginine vasopressin (AVP) and adrenocorticotropin (ACTH) are involved in the regulation of the HPA axis. Indeed, these central peptides (CRH, AVP, ACTH) and insulin are usually used to study HPA axis integrity. Literature data on the capacity of 1-deamino-8-Darginine vasopressin (DDAVP), a synthetic peptide 
with a longer life and less pressor activity than AVP, to stimulate ACTH and cortisol release in humans are controversial $(6-10)$, while it is well known that this peptide is able to release cortisol in ACTH-dependent Cushing's disease (11). Indeed, low-dose ACTH testing is claimed to be the most reliable tool to assess subtle adrenal insufficiency (12).

The aim of our study was to evaluate the response of ACTH and adrenal steroids to DDAVP and low-dose ACTH testing in ten premenopausal RA patients and seven age-matched healthy controls to uncover any differences in the regulation and sensitivity of the HPA axis and to confirm the presence of cortisol resistance in RA.

\section{Subjects and methods}

We studied ten patients $(39.8 \pm 7.4$ (s.D.) years) who had RA according to the criteria of the American Rheumatism Association (13) and seven age-matched (34.1 \pm 9.6 (s.D.) years) healthy women as controls. At the time of evaluation, no patient with RA was on glucocorticoid therapy or had received intra-articular injections of glucocorticoids during the 6 months prior to the study. Non-steroidal anti-inflammatory drugs were withdrawn 3 days before the study, which was approved by the local Ethics Committee.

In RA patients, we collected blood samples for erythrocyte sedimentation rate (normal range $2-15 \mathrm{~mm} / \mathrm{h}$ ) and C-reactive protein (normal range $0-5 \mathrm{mg} / \mathrm{l}$ ).

All patients underwent stimulus testing, in random order, with placebo, ovine CRH (oCRH) $(1 \mu \mathrm{g} / \mathrm{kg}$ body weight), UCB, Brussels, Belgium), DDAVP (10 $\mu \mathrm{g})$ (Minirin, Ferring, Malmöe, Sweden) and low-dose $(5 \mu \mathrm{g})$ ACTH (ACTH 1-24, Synacthen $250 \mu \mathrm{g}$, Ciba, Huningue, France). Blood samples were collected at the following experimental times: $-60,-30,0,+15,+30$, $+60,+90 \mathrm{~min}$. The stimuli were administered i.v. as boluses at time 0 . During each testing, blood samples for ACTH and cortisol assays were collected. Blood samples for dehydroepiandrosterone (DHEA) assay were collected at $-60,0,+15,+30,+60,+90 \mathrm{~min}$. At 0 and $+90 \mathrm{~min}$, blood samples for $\Delta 4$-androstenedione assay were collected. At each ACTH test time, blood samples were collected for 17-hydroxyprogesterone (17-OHP) assay. Baseline samples were collected for estradiol (E2), progesterone, insulin-like growth factor-I (IGF-I) and testosterone assays. Moreover, all the patients collected specimens for urine free cortisol (UFC) assay and underwent early morning and late afternoon blood sampling for ACTH and cortisol.

Tests were started at $1200 \mathrm{~h}$, when the HPA axis secretion tends to decline, to improve the sensitivity to the test and avoid misinterpretation of the results. Tests were performed in a random order, 2 days apart, in the follicular phase (3rd-5th day) of two different menstrual cycles; at the beginning of each test, a fine needle was inserted into the forearm and kept patent by a saline solution. ACTH, cortisol and E2 were assayed as already reported (8). UFC was assayed by RIA for cortisol, after extraction with dichloromethane. Testosterone was assayed by RIA (DPC, Los Angeles, CA, USA). Assay sensitivity was $0.1 \mathrm{nmol} / \mathrm{l}$; the interassay coefficient of variation was $5 \%$ at $3.5 \mathrm{nmol} / \mathrm{l}$, while the intra-assay coefficient of variation was $11 \%$ at $2.8 \mathrm{nmol} / \mathrm{l}$. Plasma IGF-I was assayed after acidethanol extraction according to Barreca et al. (14). DHEA was assayed by RIA (Diagnostic Systems Laboratories, Webster, TX, USA). Assay sensitivity was $0.03 \mathrm{nmol} / \mathrm{l}$. The intra-assay coefficient of variation was $3.8 \mathrm{ng} / \mathrm{ml}$ at $9.0 \mathrm{nmo} / \mathrm{l}$ and $2.7 \%$ at $34.1 \mathrm{nmol} / \mathrm{l}$, while the interassay coefficient of variation was $8.6 \%$ at $9.0 \mathrm{nmol} / \mathrm{l}$ and $3.8 \%$ at $33.5 \mathrm{nmol} / \mathrm{l}$. Cross-reactivity of the DHEA antiserum with DHEA sulfate was $0.02 \%$. 17-OHP was assayed by RIA (Immunotech, Marseille, France). Assay sensitivity was $0.2 \mathrm{nmol} / \mathrm{l}$; intra-assay coefficient of variation was $6.5 \%$ at $3.0 \mathrm{nmol} / \mathrm{l}$ and $5.5 \%$ at $20.5 \mathrm{nmol} / \mathrm{l}$; the interassay coefficient of variation was 8.3 at $1.7 \mathrm{nmol} / \mathrm{l}$ and $7.4 \%$ at $11.2 \mathrm{nmol} / \mathrm{l}$. $\Delta 4$ androstenedione was assayed by RIA (Diagnostic Systems Laboratories). Assay sensitivity was $0.1 \mathrm{nmol} /$ l. The intra-assay coefficient of variation was $5.6 \%$ at $2.5 \mathrm{nmol} / \mathrm{l}$, and $4.3 \%$ at $8.1 \mathrm{nmol} / \mathrm{l}$. The interassay coefficient of variation was $9.8 \%$ at $2.1 \mathrm{nmol} / \mathrm{l}$, and $6.0 \%$ at $7.0 \mathrm{nmol} / \mathrm{l}$. Area under curves $(\mathrm{AUC})_{0-90}$ were calculated by trapezoidal integration. In accordance with Todd \& Lawrence (15), we defined a significant response to oCRH as an increase of $50 \%$ or greater in the value of ACTH and an increase of $20 \%$ or greater in that of cortisol with reference to baseline values. Data were expressed as means \pm s.E.M. if not otherwise specified. Statistical analysis was performed by a twoway ANOVA stratified on the basis of the effect of the groups studied, the tests carried out and the repeated measures. The procedure used was the SAS general linear model procedure. Statistical analysis of E2, testosterone, UFC, IGF-I and 17-OHP data was performed by unpaired Student's $t$-test. $P$ values were expressed when they fell between 0.001 and 0.20 . Statistical significance was assumed at $P<0.05$.

\section{Results}

No significant difference in age, body mass index, testosterone and mean E2 levels of the tests was found between RA patients and controls. IGF-I levels were significantly lower $(P<0.01)$ in RA patients $(110.6 \pm$ $6.4 \mu \mathrm{g} / \mathrm{l})$ than in controls $(207.0 \pm 37.9 \mu \mathrm{g} / \mathrm{l})$. Baseline and peak levels of ACTH, cortisol and DHEA during testing are shown in Table 1 . Within each group, no significant difference was found in baseline ACTH and adrenal steroids except for DHEA levels in placebo and DDAVP tests (Table 1). In RA patients, mean baseline DHEA $(11.4 \pm 1.0 \mathrm{nmol} / \mathrm{l})$ and $\Delta 4$-androstenedione $(4.3 \pm 0.5 \mathrm{nmol} / \mathrm{l})$ levels were significantly $(P<0.05)$ lower than in controls $(17.7 \pm 1.4 \mathrm{nmol} / \mathrm{l}$ and $5.8 \pm$ 
Table 1 Baseline and peak levels (mean \pm S.E.M.) of ACTH and adrenal steroids in the patients studied.

\begin{tabular}{|c|c|c|c|c|c|}
\hline & \multirow{2}{*}{$\begin{array}{l}\text { Hormone } \\
\text { (units) }\end{array}$} & \multicolumn{2}{|c|}{ Controls } & \multicolumn{2}{|c|}{$\mathbf{R A}$} \\
\hline & & Basal & Peak & Basal & Peak \\
\hline Placebo & $\begin{array}{l}\text { Cortisol (nmol/l) } \\
\text { ACTH (pmol/l) } \\
\text { DHEA (nmol/l) }\end{array}$ & $\begin{array}{c}193.7 \pm 27.3 \\
2.4 \pm 0.5 \\
17.6 \pm 3.2^{*}\end{array}$ & $\begin{array}{l}- \\
- \\
-\end{array}$ & $\begin{array}{c}238.1 \pm 30.6 \\
5.1 \pm 1.7 \\
10.2 \pm 1.7\end{array}$ & $\begin{array}{l}- \\
- \\
-\end{array}$ \\
\hline DDAVP & $\begin{array}{l}\text { Cortisol (nmol/l) } \\
\text { ACTH (pmol/l) } \\
\text { DHEA (nmol/l) }\end{array}$ & $\begin{array}{c}340.6 \pm 71.7 \\
5.0 \pm 1.2 \\
20.0 \pm 2.8^{\star \star \star}\end{array}$ & $\begin{array}{c}350.8 \pm 71.2 \\
7.0 \pm 1.6^{\star \star} \\
23.8 \pm 4.1\end{array}$ & $\begin{array}{c}235.1 \pm 26.5 \\
4.4 \pm 1.0 \\
11.0 \pm 2.0\end{array}$ & $\begin{array}{c}250.6 \pm 25.1 \\
9.6 \pm 4.3 \\
21.0 \pm 3.4^{\star \star \star \star}\end{array}$ \\
\hline $\mathrm{CRH}$ & $\begin{array}{l}\text { Cortisol (nmol/l) } \\
\text { ACTH (pmol/l) } \\
\text { DHEA (nmol/l) }\end{array}$ & $\begin{array}{c}221.0 \pm 28.7 \\
3.9 \pm 0.8 \\
14.5 \pm 2.4\end{array}$ & $\begin{array}{c}518.0 \pm 34.8^{\circ} \\
13.5 \pm 3.2^{\circ 0} \\
39.0 \pm 6.5^{\circ 00}\end{array}$ & $\begin{aligned} 236.0 & \pm 24.0 \\
3.4 & \pm 1.3 \\
12.4 & \pm 2.1\end{aligned}$ & $\begin{array}{r}623.5 \pm 62.4^{\circ} \\
9.8 \pm 2.1^{\circ 0} \\
36.6 \pm 7.0^{\circ 00}\end{array}$ \\
\hline АСТН & $\begin{array}{l}\text { Cortisol }(\mathrm{nmol} / \mathrm{l}) \\
\text { DHEA (nmol/l) } \\
17-\mathrm{OHP}(\mathrm{nmol} / \mathrm{l})\end{array}$ & $\begin{array}{c}274.3 \pm 45.5 \\
18.7 \pm 3.4 \\
0.9 \pm 0.2\end{array}$ & $\begin{array}{c}733.3 \pm 69.0^{\circ 000} \\
67.2 \pm 13.1^{\wedge} \\
5.5 \pm 1.4\end{array}$ & $\begin{array}{c}343.3 \pm 38.6 \\
12.1 \pm 2.1 \\
1.0 \pm 0.3\end{array}$ & $\begin{array}{c}868.8 \pm 73.1^{0000} \\
35.9 \pm 6.9^{\wedge} \\
5.3 \pm 1.5\end{array}$ \\
\hline
\end{tabular}

${ }^{\star} P<0.05$ vs RA; ${ }^{* *} P<0.05$ vs basal; ${ }^{* * *} P<0.05$ vs RA; ${ }^{* * *} P<0.01$ vs basal.

${ }^{\circ} P<0.01$ vs basal; ${ }^{\circ 0} P=0.01$ vs basal; ${ }^{\circ 00} P<0.01$ vs basal; ${ }^{\circ 000} P<0.01$ vs basal;

${ }^{\wedge} P<0.01$ vs basal and $P<0.05$ vs RA; ${ }^{\wedge} P<0.01$ vs basal.

$0.5 \mathrm{nmol} / \mathrm{l}$ respectively). Early morning cortisol levels were slightly, but significantly $(P<0.05)$, higher in controls $(527.7 \pm 29.8 \mathrm{nmol} / \mathrm{l})$ than in RA patients $(363.8 \pm 42.8 \mathrm{ng} / \mathrm{ml})$. Both groups showed a significant diurnal cortisol rhythm, while only controls showed a significant ACTH rhythm. No difference in UFC was found between RA patients $(206.7 \pm 39.7 \mathrm{nmol} / 24 \mathrm{~h})$ and controls $(181.3 \pm 42.8 \mathrm{nmol} / 24 \mathrm{~h})$. After placebo, no significant difference in ACTH $(P=0.20)$ or cortisol AUC was found between RA patients and controls (Figs 1 and 2). Baseline DHEA levels were significantly $(P<0.05)$ higher in controls than in RA patients (Table 1) while DHEA AUC during placebo was slightly, but not significantly $(P=0.10)$, higher in controls than in RA patients (Fig. 3). After DDAVP administration no significant cortisol response was found either in RA patients or in controls (Table 1, Fig. 2), while a significant $(P<0.05)$ ACTH increase was found in controls (Table 1, Fig. 1). No significant DHEA response was found after DDAVP administration in controls, while in RA patients DDAVP was able to induce a significant $(P<0.01)$ DHEA release (Table 1). However, incremental DHEA AUC after DDAVP was slightly, but not significantly $(P=0 \cdot 10)$, higher than DHEA AUC during placebo, being similar to controls (Fig. 3). After oCRH administration similar significant ACTH $(P=0.01)$ and cortisol $(P<0.01)$ responses (peak and AUC) were found in both RA patients and controls (Table 1, Figs 1 and 2). ACTH and cortisol AUCs were significantly $(P<0.05)$ higher after oCRH than after placebo in both groups studied (Figs 1 and 2). After oCRH administration, a similar significant $(P<0.01)$ DHEA increase was found in both RA patients and in controls (Table 1, Fig. 3). After low-dose ACTH testing, a similar significant $(P<0.01)$ cortisol and DHEA response was found both in RA patients and controls
(Table 1, Figs 2 and 3). Indeed, DHEA peaks after ACTH were significantly higher $(P<0.05)$ in controls than in RA patients (Table 1) as were DHEA AUCs (controls $4280.8 \pm 749 \mathrm{nmol} / \mathrm{l}$ per $90 \mathrm{~min}$, RA patients $2196.0 \pm$ $321.8 \mathrm{nmol} / \mathrm{l}$ per $90 \mathrm{~min}, P<0.01$ ) (Fig. 3). After the low-dose ACTH test, a similar significant $(P<0.01)$, though not abnormal, 17-OHP response was found in both groups. After oCRH administration, four RA patients and three controls complained of facial flushing; while after DDAVP, two RA patients and three controls complained of facial flushing and slight headache.

\section{Discussion}

It has recently been suggested that a dysfunction of the HPA axis can contribute to the development or persistence of inflammatory disease (16), an hypothesis supported by findings in animal models of RA (5). In humans, evidence for the anti-inflammatory effects of the HPA includes the exacerbation of RA by the administration of metyrapone (17). Few studies on HPA axis function have been performed in humans with $\mathrm{RA}$, and conclusions are conflicting. Increased basal ACTH levels and an ACTH response to oCRH similar to controls have been reported in RA patients treated with low-dose steroids, while this response was higher than in controls when the steroid was withheld; indeed, baseline and oCRH-stimulated cortisol levels were normal $(18,19)$. Recent literature data have shown no significant difference either in 24-h integrated ACTH and cortisol levels or in oCRH-stimulated ACTH and cortisol levels between RA patients and healthy controls (20). Our findings are in agreement with these latter findings. These data could represent a partially reduced cortisol output in the setting of sustained inflammation involving an increase in levels of cytokines (especially 


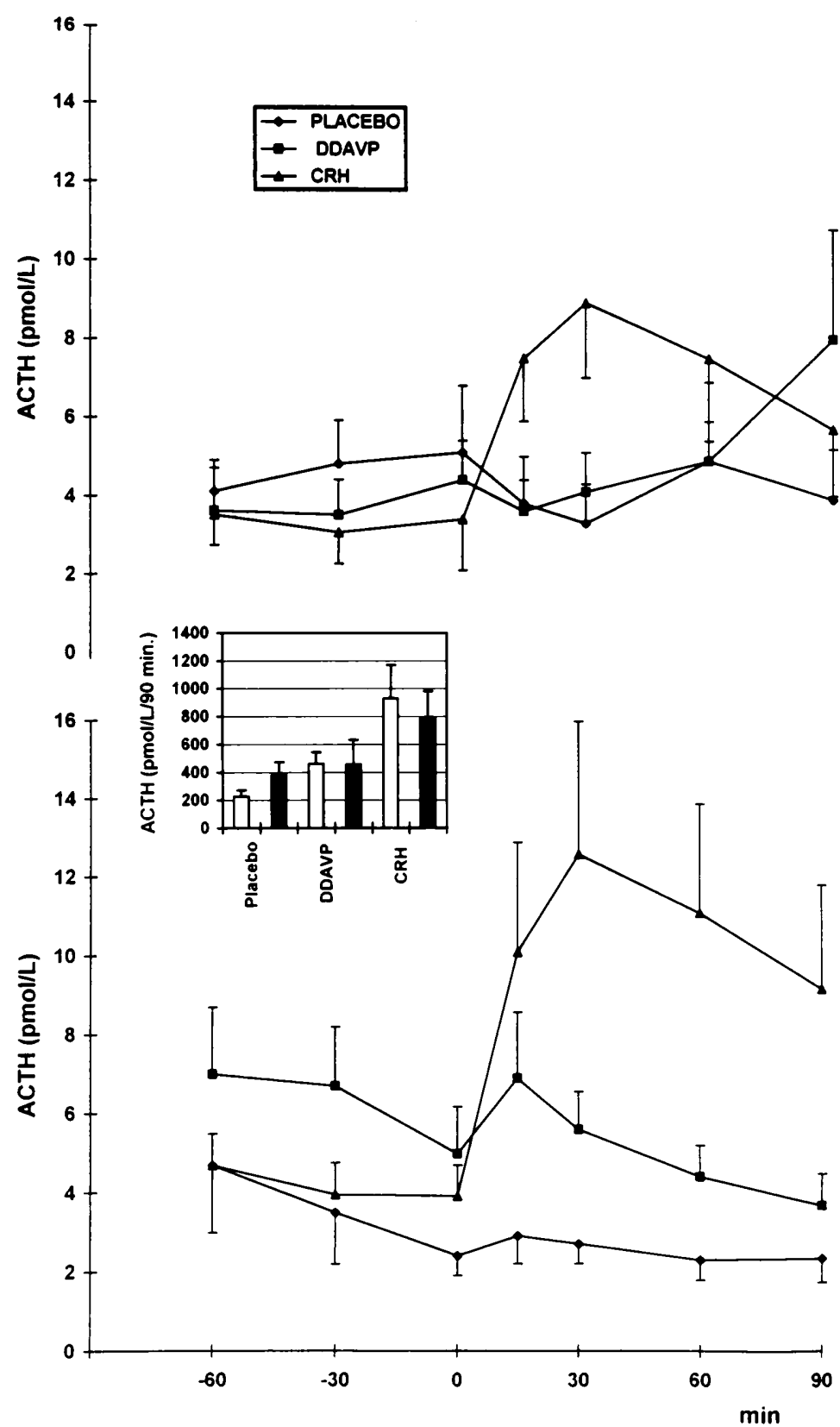

Figure $1 \mathrm{ACTH}$ responses (mean \pm S.E.M.) to placebo, DDAVP and oCRH tests in RA patients (upper panel) and controls (lower panel). Inset, ACTH AUC in controls (open bars) and RA patients (solid bars).

interleukin (IL)-6), which are known to be potent central and peripheral activators of the HPA axis (20). On the other hand, the similar, though not abnormal, 17-OHP response to ACTH in RA patients and in controls found in our work implies that an enzymatic defect (i.e. P450 21-hydroxylase) is not responsible for the 'inadequate' cortisol levels found in RA. During DDAVP administration we found no ACTH or cortisol responses in RA patients, while we found a significant ACTH, but not cortisol, increase in controls. While it is well known that DDAVP is able to stimulate ACTH and cortisol in ACTH-dependent Cushing's disease (11), literature data on ACTH and cortisol responses to DDAVP in normals are controversial (6-10). However, DDAVP probably possesses, per se, a slight ACTH releasing activity whose statistical significance seems to depend on many variables (time of sampling, baseline ACTH levels, drug dose and way of administration). In our work the absence of a significant ACTH and cortisol response to DDAVP prompts us at least to exclude that, unlike in Cushing's disease, V3 receptors are overexpressed in RA. It nevertheless remains difficult to 


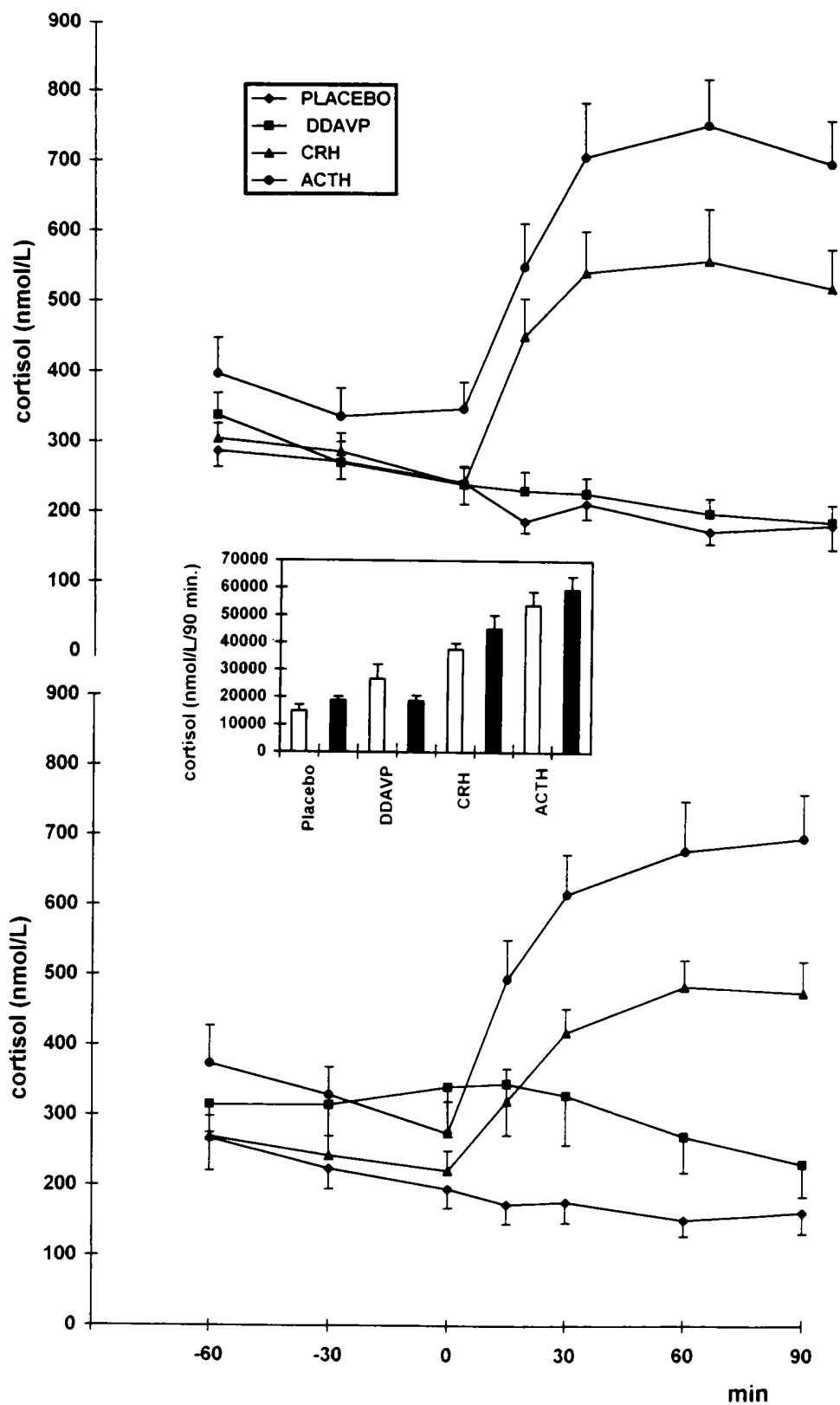

Figure 2 Cortisol responses (mean \pm S.E.M.) to placebo, DDAVP, oCRH, and low-dose ACTH tests in RA patients (upper panel) and controls (lower panel). Inset, cortisol AUC in controls (open bars) and RA patients (solid bars).

explain the discrepancy between ACTH (present) and cortisol response (absent) to DDAVP in controls; a possible hypothesis is that the peptide is able to induce a significant, but only transient, ACTH release, which is unable to cause a significant cortisol increase. Standard ACTH testing has been used for many years to diagnose adrenal insufficiency (21). The commonly used ACTH dose $(250 \mu \mathrm{g})$ is clearly 'supraphysiological', and may induce false-positive cortisol responses, and thus be unable to distinguish patients with subtle adrenal insufficiency. Indeed, low ACTH doses $(1-5 \mu \mathrm{g})$ are able to detect subtle deficiencies of the HPA axis (12,
22), even if literature data about the ability of $1 \mu \mathrm{g}$ to elicit maximal cortisol stimulation are controversial (23). We therefore used a $5 \mu \mathrm{g}$ ACTH test to study adrenal reserve in RA patients, and we found no difference in cortisol response between RA patients and controls. This finding suggests that adrenal cortisol reserve and sensitivity to exogenous ACTH are preserved in RA, even though cortisol output can be regarded as insufficient in the setting of a sustained inflammatory process. In our work, mean baseline DHEA levels of the tests were lower in RA patients than in controls as already reported by some authors $(1,2)$ 


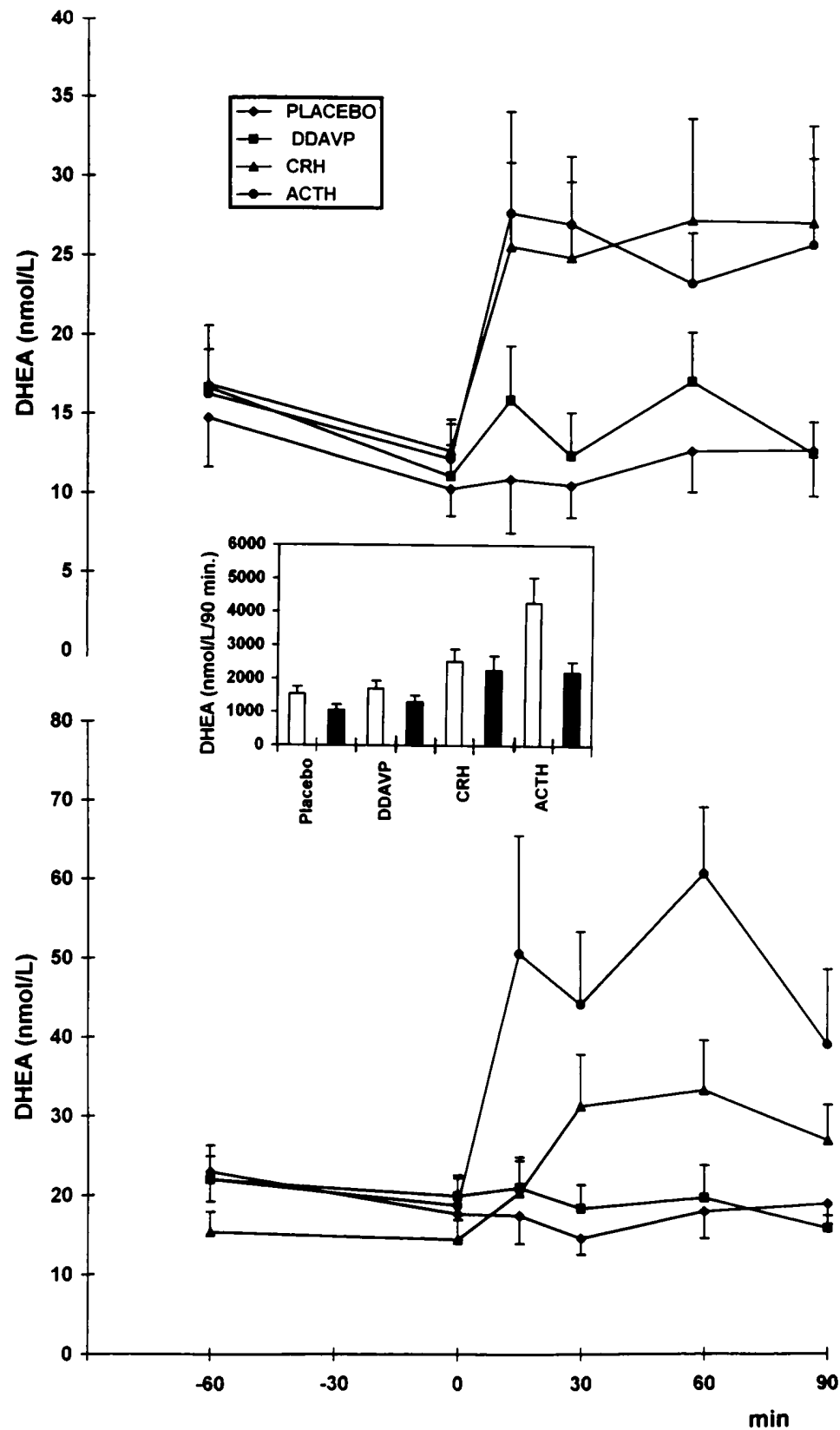

Figure 3 DHEA responses (mean \pm S.E.M.) to placebo, DDAVP, oCRH, and low-dose ACTH tests in RA patients (upper panel) and controls (lower panel). Inset, DHEA AUC in controls (open bars) and RA patients (solid bars).

but not by others $(24,25)$. Indeed, we found a significant but transient DHEA increase after DDAVP administration in RA patients but not in controls. It is difficult to explain clearly this finding. Interestingly, however, previous literature data have shown that the diurnal rhythm of AVP is upregulated in RA, and that the excessive AVP production possesses a proinflammatory action in arthritis-prone Lewis rats (26). So, the DHEA response to DDAVP could reveal a dysregulation of the AVP system. No difference in DHEA response to oCRH was found in our subjects, while a significantly reduced DHEA level (peak and integrated area) after low-dose ACTH was seen in RA patients compared with the controls. This finding seems to offer a dynamic confirmation of the reduced adrenal steroid secretion present in RA and could imply both a reduced adrenal sensitivity to low-dose ACTH stimulation and a decreased synthesis. In fact, it is possible to hypothesize that the reduced baseline and ACTHstimulated DHEA levels found in RA could be partially due to a decreased adrenal P450 17,20 lyase activity. It is well known that androgens are positive regulators of 
the growth hormone (GH)-IGF-I axis (27). Previous literature data have shown that, in comparison with controls, RA patients have, almost significantly, reduced plasma IGF-I levels and clearly reduced plasma IGF-II and insulin-like growth factor-binding protein-3 levels which, however, are increased in synovial fluid (28). Previous literature data have shown a blunted $\mathrm{GH}$ response after growth hormone-releasing hormone in RA patients when compared with controls, and this finding might be due to the increased IL-1 levels found in these patients which is known to stimulate somatostatin synthesis and release in rat hypothalamus (29). The reduced IGF-I levels found in our RA patients might not therefore be merely secondary to a chronic illness such as RA, but might be due to multiple factors such as a reduced activity of the GH-IGF-I axis and a passage of the peptide from the circulation to the synovial space (28). Finally, while confirming the reduced adrenal steroid levels in RA, our study did not confirm the previously described cortisol resistance, thus suggesting that baseline and dynamic ACTH and cortisol levels may be 'normal' but inadequate in the setting of a sustained inflammatory disease. The reduced basal and low-dose ACTH-induced DHEA levels could reflect both a reduced sensitivity of the adrenal gland to exogenous ACTH and a reduced steroid synthesis due to a partial adrenal enzymatic defect (P450 17,20 lyase). In the pathogenesis of the reduced IGF-I levels multiple factors (central and peripheral) might be involved.

\section{Acknowledgements}

This work was supported by a grant from the Italian Ministry of Scientific and Technological Research (Murst 60\%) to M C.

\section{References}

1 Feher KG, Feher T \& Meretey K. Plasma dehydroepiandrosterone, dehydroepiandrosterone sulphate and androsterone sulphate levels and their interaction with plasma proteins in rheumatoid arthritis. Experimental and Clinical Endocrinology 198484 197202.

2 De La Torre B, Hedman M, Nilsson E, Olesen O \& Thorner A. Relationship between blood and joint tissue DHEAS levels in rheumatoid arthritis and osteoarthritis. Clinical and Experimental Rheumatology 199311 597-601.

3 Cutolo M, Balleari E, Giusti M, Intra E \& Accardo S. Androgen replacement therapy in male patients with rheumatoid arthritis. Arthritis and Rheumatism 199134 1-5.

4 Laue L, Kawai S, Brandon DD, Brightwell D, Barnes K, Knazek RA et al. Receptor-mediated effects of glucocorticoids on inflammation: enhancement of the inflammatory response with a glucocorticoid antagonist. Journal of Steroid Biochemistry 198829 591-598.

5 Sternberg EM, Hill JM, Chrousos GP, Kamilaris T, Listwak SJ, Gold PW et al. Inflammatory mediator-induced hypothalamicpituitary-adrenal axis activation is defective in streptococcal cell wall arthritis susceptible Lewis rats. Proceedings of the National Academy of Sciences of the USA $1989862374-2378$.

6 Rado JP \& Juhos E. Effect of 1-deamino-8-D-arginine vasopressin (DDAVP) on plasma cortisol (hydrocortisone). Journal of Clinical Pharmacology $197616333-337$.
7 Gaillard RC, Riondel AM, Ling N \& Muller AF. Corticotropin releasing factor activity of CRF 41 in normal man is potentiated by angiotensin II and vasopressin but not by desmopressin. Life Sciences 198843 1935-1944.

8 Foppiani L, Sessarego P, Valenti S, Falivene MR, Cuttica CM \& Giusti M. Lack of effect of desmopressin on ACTH and cortisol responses to ovine corticotropin-releasing hormone in anorexia nervosa. European Journal of Clinical Investigation 199626 879883 .

9 Maraschini C, Moro M, Invitti C \& Cavagnini F. The desmopressin test in the differential diagnosis of Cushing's disease. Journal of Endocrinological Investigation 199720 (Suppl to no. 4), no 35, p 11.

10 Maraschini C, Moro M, Invitti C \& Cavagnini F. ACTH and cortisol response to desmopressin in anorexia nervosa. Abstract Book of the 79th International Congress of Endocrinology June 11-14 1997, Minneapolis, USA, p 460. Bethesda: Endocrine Society.

11 Malerbi DA, Mendonca BB, Liberman B, Toledo SPA, Corradini MCM, Cunha-Neto MB et al. The desmopressin stimulation test in the differential diagnosis of Cushing's syndrome. Clinical Endocrinology 199338 463-472.

12 Daidoh H, Morita H, Mune T, Murajama M, Hanafusa J, Ni H et al. Responses of plasma adrenocortical steroids to low-dose ACTH in normal subjects. Clinical Endocrinology 199543 311-315.

13 Arnett FC, Steven ME, Bloch DA, Dennis JMS, Fries JE, Norman SC et al. The American Rheumatism Association 1987 revised criteria for the classification of rheumatoid arthritis. Arthritis and Rheumatism 198831 315-324.

14 Barreca A, Ciccarelli E, Minuto F, Bruzzi P, Giordano G \& Camanni F. Insulin-like growth factor-I and daily growth hormone profile in the assessment of active acromegaly. Acta Endocrinologica $1989120629-635$.

15 Todd BK \& Lawrence C. The Cushing Syndrome: an update on diagnostic test. Annals of Internal Medicine $1990112434-444$.

16 Wilder RL \& Sternberg EM. Neuroendocrine hormonal features in rheumatoid arthritis and related conditions. Current Opinions in Rheumatology $1992191692-1696$.

17 Saldanha C, Tougas G \& Grace E. Evidence for anti-inflammatory effect of normal circulating plasma cortisol. Clinical and Experimental Rheumatology 19864 365-366.

18 Hall J, Morand EF, Medbak S, Zaman M, Perry L, Goulding NJ et al. Abnormal hypothalamic-pituitary-adrenal axis function in rheumatoid arthritis. Arthritis and Rheumatism $1994371132-$ 1137.

19 Cash JM, Crofford LJ, Gallucci WT, Sternberg ET, Gold PW, Chrousos GP et al. Pituitary-adrenal axis responsiveness to ovine corticotropin releasing hormone in patients with rheumatoid arthritis treated with low dose prednisone. Journal of Rheumatology $1992191692-1696$.

20 Crofford LJ, Kalogeras KT, Mastorakos G, Magiakou MA, Wells J, Kanik KS et al. Circadian relationships between interleukin (IL)-6 and hypothalamic-pituitary-adrenal axis hormones: failure of IL-6 to cause sustained hypercortisolism in patients with early untreated rheumatoid arthritis. Journal of Clinical Endocrinology and Metabolism 199782 1279-1283.

21 Wood JB, James VHT, Frankland AW \& Landon J. A rapid test of adrenal function. Lancet 1965 i 43.

22 Rasmuson S, Olsson T \& Hagg E. A low-dose ACTH test to assess the function of the hypothalamic-pituitary-adrenal axis. Clinical Endocrinology 199644 151-156.

23 Tordjman K, Jaffe A, Grazas N, Apter C \& Stern N. The role of the low dose $(1 \mu \mathrm{g})$ adrenocorticotropin test in the evaluation of patients with pituitary diseases. Journal of Clinical Endocrinology and Metabolism 199580 1301-1305.

24 Spector TD, Perry LA, Tubb G \& Huskisson EC. Androgen status of females with RA (Letter). British Journal of Rheumatology 198726 316-318.

25 Arnalich F, Benito-Urbina S, Gonzales Gancedo P, De Miquel E \& Gijon Banos J. Elevations des androgenes plasmatique chez les femmes menopausees atteintes de polyarthrite rhumatisme. Revue du Rhumatisme Maladies Osteo Articularies 199057 509-512. 
26 Chikanza IC, Petrou P, Panayi GS \& Chrousos G. Arginine vasopressin (AVP) secretion in rheumatoid arthritis: pathophysiological implications. Arthritis and Rheumatism 199538 Abstract no 382, p 216

27 Martha PM Jr, Rogol AD, Veldhuis JD, Kerrigan JR, Goodman DW \& Blizzard RM. Alteration in the pulsatile properties of circulating growth hormone concentration during puberty in boys. Journal of Clinical Endocrinology and Metabolism 198969 563-570.

28 Fernihough JK, Billingham MEJ, Cwyfan-Hughes S \& Holly JMP. Local disruption of the insulin-like growth factor system in the arthritic joint. Arthritis and Rheumatism $1996391556-$ 1565.

29 Templ E, Koeller M, Riedl M, Wagner O, Graninger W \& Luger A. Anterior pituitary function in patients with newly diagnosed rheumatoid arthritis. British Journal of Rheumatology 199635 350-356.

Received 28 July 1997

Accepted 15 December 1997 